\title{
Marketing in Higher Education: Postgraduate Programs in Technological Educational Institute of Thessaly
}

\author{
Grammenou Kassiani $^{1}$ \\ Karagiorgos loannis ${ }^{1}$ \\ Blanas Nikolaos ${ }^{1}$ \\ Grigoriou loanna ${ }^{2}$ \\ Tzika Heidy ${ }^{1}$ \\ Tzoumerkioti Kleio ${ }^{1}$ \\ Sideridou Alexandra-Antonia ${ }^{1}$ \\ ${ }^{1}$ Department of Business Administration - TEl of Thessaly \\ ${ }^{2}$ University of Staffordshire
}

Doi: 10.1515/ajis-2017-0022

\section{Abstract}

The Departments of Higher Education that have incorporated postgraduate courses in their curriculum must acquire provision and adaptability mechanisms so that the courses can correspond to the current and future needs of their students. Important factors, such as many disadvantages that the extremely competitive postgraduate courses abroad face, compared to the postgraduate courses in Greece, lead the potential students to choose the Greek ones. This research paper aims to find the right methodology for the postgraduate courses to attract more students. Specifically the research will be conducted through questionnaires, using Likert method and SPSS system for the processing of data. Our goal is to collect primary data from active postgraduate students of the Technological Educational Institute of Thessaly. The results of the research will serve as useful tools for the administrative members of both Higher Education Universities and Technological Education Institutes, as well for the teachers, since they can showcase the Greek postgraduate courses in comparison to the ones abroad.

Keywords: Economics of Education, Marketing, Higher Education, Postgraduate Courses

\section{Introduction}

During the current economically difficult period for Greece, when there is a daily rapid shrinkage in the labor market and a tremendous high number of young people who seek a position in this labor market, having a mere basic college degree is not enough. Nowadays a wide range of resources is allocated to youth in comparison to what was available to the previous generations. Due to this, labor market is much more competitive in comparison to what it was twenty years ago. A college degree, a certification degree of a foreigner language and a certification of computer skills are only some of the basic parents provide their children with. Sports, Music, Arts, Dancing or whatever else a parent considers important for his child to know, are a few more capabilities offered to youth today. Ten or twenty years ago, all of the above qualifications were more than enough for someone 
to acquire a good high paid job, while nowadays the same qualifications are only considered as basic skills. A CV which includes only the today's basic qualifications is not considered competitive enough and is not possible to stand apart in the crowd. So further studies are the only solution, and nowadays many college graduates seek a postgraduate course.

Under these circumstances, more young people choose to continue their studies abroad, and most of the Greek Academic Institutions strive to cope with this reality. The main goal of this research is to help that the Greek postgraduate courses become more competitive with the foreign ones, and therefore attract Greek and, why not, foreign students. The Greek postgraduate courses , subjected to law regulations (which forbid making the Greek courses more attractive to foreign ones through such schemes as e.g. shorter required time to get a degree) can use important marketing tools to their advantage. To begin with, for a better understanding of this research, here is a presentation of what we believe are the most important conceptual definitions.

W. Pride et al (2010) defines Marketing as an activity, as all the institutions and processes used for the creation, the communication, the delivery and the exchange of valuable offers to the customers, the collaborators and the society in general. The basic Marketing operations include buying and selling, transportation, storage, financing, standardization, undertaking dangers and collecting information from the market.

The marketing of relations refers to the combined marketing decisions and activities so that a long-term satisfactory relation with customers can be established. The marketing of relations increases the confidence of the customers to the business, and so does the understanding of the business of customers' needs and wants. This is why successful sellers meet the customers' needs and throughout the years try to increase the "product value" for the buyers (Pride et al., 2010; Leledakis, 2008).

When talking about marketing in education, we talk about the whole means by which the school communicates and promotes its objectives, values and products to the students, parents, stuff and society in general. In order for the business (organization's) objectives to be successful, the customer's needs should be recognized, foreseen and satisfied. Marketing in education is a basic management operation and without it no school can survive in the competitive reality of today. Nowadays, school not only needs to be effective, but it should also transmit its effective image towards parents and its partners (Siopi, 2013). According to L. 4009/2011 "Greek Universities have postgraduate courses, which are part of the strategic planning of each institution, they aim to promote knowledge, research development and the satisfaction of the Greek educational, research and development needs, they have scientific consistency, they refer to study provinces related to the bachelor's courses and they fulfill the requirements of high level studies".

Universities have the exclusive responsibility for postgraduate programs (L. 3685/2008), which should be related to the specialties of the graduate degrees. For their creation, the collaboration between college departments and recognized universities abroad, is possible. Postgraduate courses must initially be approved by the University Rector and then they are sent to the Ministry of Education for the final authorization (Leledakis, 2008). A postgraduate course requires financial as well as other resources, which can be collected from donations, public or private sponsors, tuition fees, community or research programs and subsidies through the State budget, the whole process supervised by the Director of the course. The duration of a course is up to eight years with possibility of extension. The Ministry of Education finances prioritized postgraduate programs, according to the national needs. College graduates from Greece and abroad can be accepted to postgraduate courses when their bachelor degree is equivalent to a master degree curriculum. The candidates must present a certification confirming their competence of the Greek language. Such a certification can be obtained after attending a special Greek language course, the duration of which is two months minimum. An individual member of the teaching stuff is appointed to each postgraduate student so that she/he can supervise, watch and check the student's progress (Gounaris et al., 2006).

\section{Organization of the Technological Educational Institute of Thessaly TEI}

The Technological Educational Institute of Thessaly TEI was founded in 1973 and has three 
branches located in Larissa, Karditsa and Trikala respectively. The total campus area is of 1,540 acres, of which 121 acres are occupied by the buildings. The Institution consists of twenty departments and courses directions, while the number of the registered students is 19.500 . The departments located in the city of Larissa are fully equipped with mechanical and laboratory equipment, with new building infrastructures for each of the four faculties, as well as with modern library, stables, canteen etc. Care is taken for the comfort of the students' life. For that purpose there is a restaurant serving 3.000 free meals every day, a dormitory with a capacity of 600 beds, an indoor gym and outdoor courts (Sdrolias et al., 2014).

The institution possesses fifteen patents while the study program already includes twelve selfcontained Postgraduate Courses (PC) along with many Doctorates in collaboration with the departments of Thessaly's Universities, the Aristotle University of Thessaloniki, National and Kapodistrian University of Athens, National Technical University of Athens and Universities from abroad. As a whole the Technical Educational Institute of Thessaly is an extroverted institution which collaborates with both Greek and foreign Universities, cooperatives, municipalities of the nearby region and enterprises offering specialized problem-solving know-how for the production of new products. (OnLarissa, available on line http://teilar.gr/tei_msc.php, (www.onlarissa.gr/2016/03 /21/o-nikos-papadopoulos-xenagithike-sto-ti-thessalias/).

The Postgraduate Courses of the Technological Educational Institute of Thessaly, which we have already examined, are conducted in Greek language, are either full-time or part-time courses with a duration of three or five academic semesters. The last semester is intended for the dissertation. Each semester lasts three weeks and the whole work is graded with 90 ECTS. The main objective of these master degrees is to prepare specialized and executives who can be employed in both public and private sector institutions. Meanwhile, educational and research activities are conducted aiming at the enrichment of students' knowledge through real life experiences, aiming at the enrichment of the students' knowledge (Sdrolias et al., 2014; available on line http://teilar.gr/tei_msc.php).

\section{Questionnaire Description}

A qualitative characteristic is an attribute of individuals in a population that cannot be expressed through a single measurement unit, such as is sex, nationality, occupation etc. The qualitative data can be quantified or they can be supplemented with quantitative elements (Papanis, 2011). They occur naturally and at a great extent they are not controlled by any investigator. Thus, the researcher can infiltrate the personality of the subjects and comprehend what kind of social influences they have acculturated. The researcher also reasonably combines data, elements and situations in order to make a conclusion (Babbie, 2011). The qualitative characteristics analysis includes all kinds of processes that explain their meaning, the categorization of qualitative materials aiming to answer research questions, the control of research hypothesis or eventually the interpretation and comprehension of phenomena, processes and behaviors (Papanis, 2011; McDaniel et al., 2010; Creswell, 2002).

The hierarchy scales are used for the handling of issues concerning the gradation of answers, their intensity and their distancing from the restrictions of yes/no. These scales are very useful mechanisms for the researcher, since they incorporate a great degree of sensitivity and differentiation of the answers while at the same time result in quantitative data. Such scale is the Likert Scale. Likert Scale gives a variety of answers to a particular question or statement. It is very attractive because it gives a big range of different answers with only one dimension (that is it measures only one thing at a time) (available on line ftp://ftp.soc.uoc.gr/psycho/manola /Me8odologia/\%CC\%C5\%C8\%CF\%C4\%CF\%CB\%CF\%C3\%C9\%C1\%20\%C5\%D1\%C5\%D5\%CD \%C1\%D3\%20week10\%2014.12.07.doc).

The Important Parameters of these hierarchy scales are the following. They cannot check or prove that the respondents tell the truth. It is not known if the participants wish to comment on any issue (a problem solved with the use of open-type questions). The participants avoid to make extreme choices so that they won't be stigmatized as lavishes, resulting in the limitation of choices. One way to deal with this issue is the use of a larger scale (e.g. a seven grades scale). 
Based on Cohen et al (2008), a questionnaire can contain both open and closed type questions. An open-type question can be answered freely. This method selects information which couldn't be selected otherwise, while the respondents have the absolute responsibility for the data they have. A distinctive feature of a qualitative question is the fact that it provides for the authenticity, extent, depth, honesty of the answer. The disadvantages of these questions are:

- The handling of data

- The risk of a breach of the verbal data principle that makes it difficult to secure safe results

- The gathering and the comparison of the answers, and

- The hypothesis that all the respondents are sufficiently or equally capable to write down their opinions.

In the closed-type questions, the respondent needs to choose one of the two indicated choices. These questions are used when it is necessary the use of quantitative analysis. This is a bit risky, since there is a chance that the suggested answers might not represent and express the real answers of the respondent. The questions are separated in to two categories: yes/no questions and multiple choice questions (Pasxaloudis, 2009).

\section{Results of the Research}

Our research was conducted by printed questionnaires. The questions were distributed to one hundred active post-graduate students of T.E.I. of Thessaly of the above mentioned Postgraduate Courses (PC). These questions are divided in two main parts, in nine qualitative questions and twenty four closed type questions one of which is an open type question according to the Likert scale. We used the qualitative questions in order to determine the features of those who want to continue their studies and categorize them into classifications. $31 \%$ of the asked students were women and $69 \%$ of them were men.

The age of them was as follows:

1. $22 \%$ were $23-29$ years old.

2. $32 \%$ were $30-35$ years old.

3. $25 \%$ were $(36-40$ years old.

4. $21 \%$ were up to 41 years old.

The educational level of the students was as follows:

- $43 \%$ were graduates of T.E.I.

- $37 \%$ were graduates of Universities.

- $15 \%$ already held postgraduate title.

- $4 \%$ had Phd title of studies.

- $1 \%$ did not answer.

$83 \%$ of the students were employees, $34 \%$ of them were occupied in the private sector and $48 \%$ work in public sector. $17 \%$ were unemployed and $1 \%$ did not answer. We processed the statistics data and found the average of the answers of each question. In order to this fact, the classification of the answers was shaped to the shortest divergence. According to the average of the students' questions, we categorized the 23 questions in seven classifications. In this way, the comprehension of results was satisfactory.

The classifications are as follows:

- For educational reasons (average 4,24).

- For job reasons (average 4,00).

- For reasons concerning the achievement of personal objectives (average 3,96).

- For reasons concerning the T.E.I of Thessaly (average 3,56).

- For reasons that are only concerning PMS (average 2,97).

- For economic reasons (average 2,24).

- For reasons of various factors (average 1,93).

The question "Is knowledge investment" which had the higher grades (average 4,46) and the question "Will I acquire more culture" was in the third position with average 4,02 are included in the educational reasons, which was the most favored classification. Next to that, job reasons 
classification was the students' second most favored. In this classification included were the question "Does it offer me new professional possibilities?" which was in fourth position with average 4,01 and the question "Will I become more competitive in the work sector?" that it was in the fifth position with average 3,99. In the classification "Achievement's reasons of personal objectives", relative questions are included as follows: "Will it help me to achieve my objectives?" was the second preferable reason of students' choice with average $(4,03)$. The question "Did I want to satisfy internal and exterior motives?" was in the seventh position in the students' preference with average $(3,87)$.

The next classification concludes the reasons of choice which are about T.E.I. of Thessaly (Form 8). The questionnaire in this classification begins with the question about "the excellent teaching staff' which was in the eighth position with average $(3,87)$. Next was the question about the installations and the students' benefits which was in the tenth position with average $(3,57)$. The last question concerned the beauty of the city of Larissa as the possible reason to choose the T.E.I. of Larissa for their post graduate courses. That was in the thirteenth position with average $(3,23)$.

Next is the classification for the reasons stimulating the students to choose post graduate courses and this classification includes most of the questions. Two of these questions stood out, the first of which was about the good quality of post graduate courses and the second one was about the relation between post graduate courses and the academic degree. These had the sixth and the ninth position with average $(3,92)$ and average $(3,59)$ respectively. The following questions were: "Are post graduate courses full time studies?" with average $(3,54)$ in the $11^{\text {th }}$ position, "Do I need the certificate?" with average $(3,52)$ in the $12^{\text {th }}$ position, "Is the duration short?" with average $(3,09)$ in the $14^{\text {th }}$ position, "Were these courses my initial goal since the beginning of my studies?" with average $(2,96)$ in the $15^{\text {th }}$ position. The questions "Do I want to change the basic title of my certificate" and "Do post graduate courses seem to be easy" are in the same position with average (2, 39). Finally, the question "Have I chosen these post graduate courses because I missed the deadline to submit my application to other post graduate courses?" had the lowest average with $(1,41)$ and it was in the $23^{\text {rd }}$ position.

In spite the fact that our country faces many financial problems, the classification concerning economic criteria for the post graduate courses was in low position. The students were less interested in the questions "Did you choose post graduate courses because it was more economical?" with average $(2,57)$ and it was in the 16 th position, "Did you choose post graduate courses because of the scholarship's benefits?" with average $(1,91)$ in the $20^{\text {th }}$ position. Finally, for the postgraduate students determined to invest in knowledge the classification "reasons of other factors" occupied only low level. Some of these factors are: "no other employment / obligation at that time" with average $(2,18)$ in $19^{\text {th }}$ position, "their friends attended the same post graduate courses ( to this PP)" with average $(1,85)$ in the $21^{\text {st }}$ position, "it was imposed by the broader social environment" with average $(1,78)$ in the $22^{\text {nd }}$ position.

\section{Conclusions}

Through the selection of the classification "Educational reasons", the postgraduate students of T.E.I. of Thessaly expressed their desire to obtain further knowledge and skills as main motivation to acquire the post graduate degree This is due to the fact that they want to specialize in their sector in order to find a new and better job, to be more competitive in their jobs or to get higher salaries. Another reason that post graduate degree is considered a priority is due to the will of Greeks to participate in the lifelong learning, because in the contemporary Greek culture, family holds the education as a priority.

The second most important students' motive is to find a job and this is proved in the second classification "Job reasons". Due to the globalization of the market, the competition in the job hunting is incessant and tough. The person who has most qualifications and skills is in more advantageous position. Even if the average year percentage of unemployment in 2015 was in the very high level of $24,9 \%$, it is a fact that only $12,9 \%$ of the workforce of Greece that possesses master or doctoral title of study is unemployed, which is the lowest percentage in this level of education, while in the degree graduates the percentage of unemployment is higher at $19,47 \%$, as 
we can notice in the table of the Hellenic Statistical Authority. This fact is appreciated by the postgraduate students of TEl of Thessaly and this is proved by the highest percentage which this classification gathered. A high prestige P.M.S. in the field of the job which is sought gives an advantage to a competent job seeker. This fact is appreciated from the post graduate degree students of the Technological Educational Institute (TEI) of Thessaly and it is testified from the great numbers that this group has gathered. Consequently, a post graduate course of high prestige, related to the sought job, provides an advantage to the job seeker, since the received specialization makes her/him more competent than other competitors.

Furthermore, according to the research published in the electronic newspaper "Imerisia"(http://www.imerisia.gr/article. asp?catid=34291\&subid=2\&pubid=114085997) concerning the rank in the enterprises held by the persons participating in the research and having a post graduate degree, (see Table 2), 49,8\% of them held a lower rank as clerks. $10,7 \%$ of them held the rank of General Manager, that is the top rank. Meanwhile as far as persons with a university or TEI degree were concerned the corresponding percentages were $47,9 \%$ and $3,9 \%$ respectively.

As for the wages, 32, $3 \%$ of Master/PhD degree holders gets a salary between $1001 €$ and $2000 €, 3,6 \%$ gets a salary up to $450 €$, while 10,5 gets more than $4000 €$. In comparison, $28,2 \%$ of university graduates who participated in the research gets a salary between $1001 €$ and $2000 €$, $11,9 \%$ gets $450 €$, while $8,4 \%$ gets more than 4000 It is evident from this statistics, that the employees who hold a master or $\mathrm{PhD}$ title of studies have more possibilities to obtain a higher position in a company and can receive a better income.

Conclusively, in the classification "reasons of achievement of personal objectives" which is the third most selected as a reason to pursuit post graduate courses, we have noted that the post graduate students start to pursue their personal objectives after they have met their basic needs such as job. These objectives are usually set according to personal needs and the family's environment. So it is important to achieve the personal objectives, because an eventual failure has a negative impact on the postgraduate students and results in a feeling of failure. As for the teaching staff of the TEI of Larissa, post graduate students are concerned themselves with this teaching staff which is responsible for the transmission of necessary knowledge and techniques the students need for they development. And this is testified by the average of 3,87 of the answers. This classification includes everything regarding the facilities and supplies of the TEI of Larissa. A little more than half of the students, $59 \%$, think that the facilities and supplies factor in important to students. The convenient facilities allow for the lectures to be conducted under all safety precautions and the convenient and modern equipment helps the proper education of the students. A complete round the clock education comprises a lot of other things, such as care for comfortable living of the students, free meals, housing, a lending library, an employment office, etc. The purpose of all this is to ease the educational process. Last but not least, the city in which the TEI of Larissa is located is another important factor for the students participating in this research because they consider decent the conditions of housing, public safety, commuting, transportation, infrastructure, entertainment.

The questions of the fifth classification that exclusively include the reasons for attending a post graduate course, have a great range in the ranked answers, with the higher importance given to the quality and the objectives of the post graduate courses and the lesser importance given to questions that maybe don't concern post graduate courses students, such as the level of difficulty of the post graduate courses and the deadlines of the applications submission. It is the question concerning the fine quality of post graduate courses that obtained the highest grade and that shows that the post graduate students are very concerned about the competent teaching staff, the good facilities as well as the studies curriculum.

Other characteristics that contributed to the choice of these post graduate courses is the comprehensive studies, their limited duration, all of them being advantages over foreign post graduate courses. That's why they gathered the highest grade of the answers. The reason why the question "Do I need the degree?" has gathered 3,52\% score has to do with many factors. These factors are the following: a) public sector employees feeling themselves obliged to obtain a degree so that they can counterbalance political favoritism b) ambitious employees aiming at promotion c) unemployed persons in need of enriching their qualifications to seek a job d) persons loving lifelong 
studies. The post graduate students had set from the beginning to obtain a post graduate degree and that's why they chose this specific post graduate course, answering with an average of 2,96\% to the corresponding question, while the question "I want to change the main title of my degree?" gets the second next position with an average of $2,39 \%$. As for the last question, we see that the students persevere in pursuing their studies they have begun and go on to attain a post graduate degree.

As far as the financial reasons are concerned in the sixth group, the master students appear to be natural and this is ought to the fact that the cost of the PP in the public educational institutions fluctuate in the same levels, whereas to provide scholarships the median price is 1.91, maybe because the $83 \%$ of those, are employed and they do not have that much possibility to be selected. In the last group that includes several other reasons to choose the Postgraduate program the median price is 1.93 and shows that they were least affected from them and this is explained by the age of the students of which the $78 \%$ was older than 30 years old and as a result to have increased obligations where simultaneously, their choices were not imminently affected from the social network but from their personal needs and goals.

The TEI of Larissa should create a liaison office or something like that which will lead the postgraduate students to choose vocational training and connect them with the labor market so that they succeed in job seeking. However, because it is impossible to create a liaison office given the restrictions on the budget of the TEI of Larissa, the professors of the post graduate courses could be of great help to their students. To our opinion, the desire of the students to attend post graduate courses of good quality and fame should be the main goal of a University. For this to be achieved, the teaching staff should focus on lifelong learning within a pleasant and accessible environment for all persons and show fondness for the educational procedure. The benefit will be widespread good reputation heralded by satisfied students.

\section{References}

Babbie, E. (2011). Introduction to social research. Athens : Kritiki [in Greek].

Cohen, L., Manion, L., \& Morrison, K. (2008). Methodology of educational research. Athens : Metaixmio [in Greek].

Creswell, J. W. (2002). Educational research: Planning, conducting, and evaluating quantitative (pp. 146-166). Upper Saddle River, NJ : Prentice Hall.

Gounaris, S., \& Stathakopoulos, B. (2006). Strategic Relationship Management, Marketing and Sales for Strategic Customers. Athens : Stamoulis [in Greek].

McDaniel, Jr., \& Gates, R. (2010). Marketing Research. (8th ed.). Asia : John Wiley \& Sons, Inc.

Papanis, E. (2011). Methodology Research and Internet. Athens : Sideris [in Greek].

Paschaloudis, D. (2009). Marketing : What you need to know and do not ask. Athens: Kritiki [in Greek].

Pride, W., Hughes, R., \& Kapoor, J. (2010). Introduction to Business. (10th ed.). China : South-Western Cengage learning.

\section{Journals}

Imerisia newspaper, (2016), What salaries the Greeks get - The salaries for graduates and graduates. [Online]4 Available: http://www.imerisia.gr/article.asp?catid=34291\&subid=2\&pubid=114085997 (September 9, 2016) [in Greek].

Leledakis, G., (2008), Marketing - Economy - Businesson. [Online] Available: http://repository.edulll.gr/edulll/retrieve/3116/912.pdf (September 9, 2016) [in Greek].

Sdrolias, L., Amiradis, C., Kakkos, N., \& Aspridis, G. (2014). Ein Strategischer Ansatz Zur Rolle Und Beitrag Der Hochschuleinrichtungen Zur Lokalen Und Regionalen Entwicklung Während Der Wirtschaftskrise: Der Fall Der Abteilung Für Betriebswirtschaftslehre Vom Tei Thessalien. Zeitschrift für die Regionale Wissenschaft, (1), 47-62 [in German].

Siopi, Eleftheria, (2013), Greek primary education in the light of service marketing. [Online] Available: http://docplayer.gr/672090-Diatmimatiko-programma-metaptyhiakon-spoydon-sti-dioikisi-epiheiriseondiplomatiki-ergasia.html (September 9, 2016) [in Greek]. 


\section{Institutional Texts}

L. 3685/2008. Institutional framework for postgraduate studies. Official Gazette Government: 148 $116-07-2008$ [in Greek].

L. 4009/2011. Structure, operation, quality assurance of studies and internationalization of Higher Education Institutions. Official Gazette Government: 195 $/ 6-9-2011$ [in Greek].

\section{Internet}

Manola, Anastasia, (2008), Research methodology. [Online] Available: ftp://ftp.soc.uoc.gr/psycho/manola/Me8odologia/\%CC\%C5\%C8\%CF\%C4\%CF\%CB\%CF\%C3\%C9\%C1\% 20\%C5\%D1\%C5\%D5\%CD\%C1\%D3\%20week10\%2014.12.07.doc (September 9, 2016) [in Greek].

Onlarissa,(2016), Nikos Papadopoulos guided to the TEI of Thessaly. [Online] Available: www.onlarissa.gr/2016/03/21/o-nikos-papadopoulos-xenagithike-sto-ti-thessalias/ (September 9, 2016) [in Greek]. 